\title{
Allogenic Fecal Microbiota Transplantation in Clostridioides Difficile Infection: A Case Series in Mexico
}

\author{
Yolanda López-Vidal' ${ }^{1}$, José Luis Soto-Hernández ${ }^{2}$, Patricia Orduña ${ }^{3}$, René Arredondo-Hernán- \\ dez $^{3}$, Max J Schmulson ${ }^{4}$, Ángel-Mario Zárate ${ }^{5}$, Ana Carmen Cuéllar-Treviño ${ }^{1}$, Ángel Guer- \\ ra-Hernández ${ }^{1}$, Verónica Ángeles Morales ${ }^{2}$, Graciela Cárdenas ${ }^{2}$ and Samuel Ponce de León-Ro- \\ sales $^{3 *}$
}

${ }^{1}$ Department of Microbiology and Parasitology, Microbial Molecular Immunology Program, Faculty of Medicine, National Autonomous University of Mexico, Mexico

${ }^{2}$ Department of Infectious Diseases, National Institute of Neurology and Neurosurgery Manuel Velasco Suárez, Mexico

${ }^{3}$ Microbiome Laboratory, Division of Graduate Studies and Research Division, Faculty of Medicine, National Autonomous University of Mexico, Mexico

${ }^{4}$ Liver, Pancreas and Motility Laboratory (HIPAM), Research Unit in Experimental Medicine, Faculty of Medicine, National Autonomous University of Mexico, Mexico

${ }^{5}$ Gastroenterology Service, Hospital General de México Dr. Eduardo Liceaga, Mexico

*Corresponding author: Samuel Ponce de León Rosales, University Health Research Program, National Autonomous University of

Mexico, Mexico City, Mexico

\section{ARTICLE INFO}

Received: 仹June 18, 2021

Published: 䡅 June 24, 2021

Citation: Yolanda López-Vidal, José Luis Soto-Hernández, Patricia Orduña, René Arredondo-Hernández, Samuel Ponce de León-Rosales, et al., Allogenic Fecal Microbiota Transplantation in Clostridioides Difficile Infection: A Case Series in Mexico. Biomed J Sci \& Tech Res 36(5)-2021. BJSTR. MS.ID.005905.

Keywords: Fecal Microbiota Transplantation; Clostridioides Difficile Infection; Enema; Surgery; Neurological Conditions
ABSTRACT

Clostridioides difficile is a gram-positive, spore-forming bacterium that produces toxins capable of causing severe infectious diarrhea and pseudomembranous colitis in humans. We reviewed eight cases of antimicrobial therapy-resistant $C$. difficile infection (CDI) in patients with various pathologies. The diagnosis was confirmed by toxin detection and colonoscopy. Stool for fecal microbiota transplantation (FMT) was prepared from healthy selected donors; all cases received the FMT through retention enema. In most of the patients, CDI symptoms decreased within the first $24 \mathrm{~h}$ post-FMT. We carried out short-, medium-, and long-term follow-up post-FMT, which showed an $88 \%$ of efficacy. Observed efficacy is similar to the current $80-100 \%$ reported frequently, whereas the main difference with previous reports lays on the fact that half of our patients showed baseline affectations involving surgery, neurological conditions or immune system deficiency. This study provides examples for establishing solid criteria for the FMT among patients with recurrent CDI and baseline affectations. This is a small case series and results should be considered within limitations; however, it is relevant to add all experiences to build a better knowledge on this clinical tool.

\section{Background}

Clostridioides difficile has become the major cause of health care-associated diarrhea and a recognized causal agent of pseudomembranous colitis [1,2]. It is a primary infection with major recurrence rate among hospitalized patients; spore renders
Clostridioides difficile, highly transmissible and resistant to antimicrobial treatment $[1,3,4]$. Infection is characterized by toxin production leading to intestinal barrier line up areas of cell necrosis and an intense local and/or systemic inflammatory response 
[5] associated to hampered intestinal microbiota resistance to infection mainly due to antibiotic courses [2,6,7]. Fecal microbiota transplantation (FMT) has shown a remarkable treatment success rate against C. difficile infection (CDI) [8-10], and the immuneregulatory function of microbiota has prompted the use of FMT in a number of inflammatory diseases, thus expanding usefulness of technique and demanding research [11-13]. However, few reports in literature tackles response on people with neurological conditions despite the Gut-Microbiota-Brain axis and cell immunity are possibly affected [14]. FMT has been performed in patients with several neurological disorders such as autism spectrum disorder, multiple sclerosis, Parkinson's disease and diabetic neuropathy with beneficial effects, but evidence remains limited mostly among neurological, or immunocompromised patients co-occurring with CDI [15]. However, indications support similar success rates, the evidence is weak with only observational studies or case series $[16-18,19]$. On the other hand, the guidelines of the World Society of Emergency Surgery (WSES) recommended the use of FMT in surgical patients with multiple recurrences of CDI; however, the evidence is weak with only observational studies or case series [19]. In this study, we performed an allogeneic FMT on eight patients with CDI and surgery, neurological or immune conditions.

Table 1: Patients with diarrhea* associated to C. difficile.

\section{Case Series}

Retrospective clinical history file screening of eight cases of antimicrobial therapy-resistant CDI occurring among patients with Acquired Immune Deficiency Syndrome (AIDS), Central Nervous System (CNS) injury, or surgeries. Diagnostic of CDI was confirmed through immunoenzymatically detection of A/B toxins of C. difficile. The antimicrobial treatment failure, as indicated by clinical practice guidelines, persuaded the acting physicians to recommend FMT [20$22]$, whereas patients agreed on signing an informed consent. Fecal microbiota for transplant was prepared from screened, unrelated donors freely participating with the Microbiota Transplant Unit of University's Faculty of Medicine, following 2017 European Consensus criteria and directions [21]. All patients received FMT by retention enema (50 g/200 mL saline solution). Subsequently, the patients underwent close follow-up for the following $48 \mathrm{~h}$ to record short-term adverse events directly related to FMT, whereas recurrence was only discarded after 3 months of not showing any symptoms. The adverse events investigated included systemic and gastrointestinal tract. The patients' initial risk and prognostic factors are described in Table 1; while Table 2 presents the initial conditions and results of FMT in patients with CDI.

\begin{tabular}{|c|c|c|c|c|c|c|c|}
\hline Patient & Sex & $\begin{array}{l}\text { Age, } \\
\text { Years }\end{array}$ & $\begin{array}{l}\text { Date of } \\
\text { Admission }\end{array}$ & $\begin{array}{l}\text { Pre-CDI } \\
\text { Hospital Stay, } \\
\text { Days }\end{array}$ & Comorbidities & $\begin{array}{l}\text { Surgical or Invasive } \\
\text { Procedures }\end{array}$ & $\begin{array}{l}\text { AB Treatment } \\
\text { Prior to CDI }\end{array}$ \\
\hline 1 & Male & 77 & 15.09 .2016 & $17^{* *}$ & $\begin{array}{l}\text { Infectious gastroenteritis, uremic } \\
\text { syndrome, CVC-related sepsis, } \\
\text { intestinal occlusion }\end{array}$ & $\begin{array}{l}\text { Placement of CVC, } \\
\text { hemodialysis, colostomy }\end{array}$ & $\begin{array}{l}\text { DIC, CRO, CIP, } \\
\text { ETP, MEM, } \\
\text { caspofungin }\end{array}$ \\
\hline 2 & Female & 59 & 15.04 .2017 & 2 & Achalasia & Heller's myotomy & $\mathrm{N} / \mathrm{D}$ \\
\hline 3 & Female & 58 & 18.04 .2017 & 23 & $\begin{array}{l}\text { EVC (left posterior communicating } \\
\text { segment aneurysm), middle cerebral } \\
\text { artery vasospasm and infarction of } \\
\text { the same territory }\end{array}$ & $\begin{array}{l}\text { Craniotomy and aneurysm } \\
\text { clipping }\end{array}$ & $\begin{array}{l}\text { CRO, rifaximin, } \\
\text { IPM }\end{array}$ \\
\hline 4 & Female & 35 & 08.08.2017 & 20 & $\begin{array}{l}\text { Dorsal pyogenic spondylodiscitis, } \\
\text { sacrum myelitis }\end{array}$ & Dorsal corpectomy & AMK, GEN \\
\hline 5 & Female & 84 & 13.02 .2018 & 4 & $\begin{array}{c}\text { EVC (anterior communicating } \\
\text { segment aneurysm), CVC-associated } \\
\text { sepsis }\end{array}$ & $\begin{array}{l}\text { Aneurysm embolization, } \\
\text { central venous catheter, } \\
\text { gastrostomy }\end{array}$ & $\begin{array}{l}\text { CPM, AMK, VAN, } \\
\text { fluconazole }\end{array}$ \\
\hline 6 & Male & 47 & 04.10 .2017 & 31 & $\begin{array}{l}\text { HIV/AIDS 3C, complete paralysis of } \\
\text { NCIII, neuroinfection }\end{array}$ & None & $\begin{array}{l}\text { PEN, CRO, LVX, } \\
\text { SXT, Atripla, } \\
\text { fluconazole }\end{array}$ \\
\hline 7 & Male & 48 & 28.12.2017 & 6 & $\begin{array}{l}\text { EVC (right anterior cerebral artery } \\
\text { aneurysm), bifrontal infarction, CVC- } \\
\text { associated sepsis }\end{array}$ & $\begin{array}{l}\text { Embolization of ruptured } \\
\text { aneurysm, tracheostomy, } \\
\text { gastrostomy }\end{array}$ & CM, CF, CRO \\
\hline 8 & Female & 27 & 27.12.2018 & 55 & $\begin{array}{l}\text { Autoimmune encephalitis, health } \\
\text { care-associated pneumonia, } \\
\text { epilepsy, sepsis }\end{array}$ & $\begin{array}{l}\text { Central venous catheter, } \\
\text { endotracheal intubation, } \\
\text { tracheostomy, gastrostomy }\end{array}$ & $\begin{array}{l}\text { GEN, CRO, CPM, } \\
\text { VAN, ERI, CM, } \\
\text { COL, TZP, MET }\end{array}$ \\
\hline
\end{tabular}

*More than three daily evacuations with decreased consistency and increased volume and odor; **Total days. Two previous hospitalizations in the previous month; AIDS= Acquired Immune Deficiency Syndrome, AMK= amikacin, CDI=Clostridium difficile infection, $\mathrm{CIP}=$ ciprofloxacin, $\mathrm{CF}=$ cefalotin, $\mathrm{CM}=$ clindamycin, $\mathrm{CPM}=$ cefepime, $\mathrm{CRO}=$ ceftriaxone, $\mathrm{CVC}=$ central venous catheter, $\mathrm{CVD}=$ cerebrovascular disease, $\mathrm{DIC}=$ dicloxacillin, $\mathrm{ETP}=$ ertapenem, $\mathrm{GEN}=$ gentamicin, $\mathrm{HIV}=$ Human Immunodeficiency virus, $\mathrm{IPM}=$ imipenem, $\mathrm{LVX}=$ levofloxacin, $\mathrm{MEM}=$ meropenem, $\mathrm{NCIII}=$ third cranial nerve pair, $\mathrm{PEN}=$ penicillin, $\mathrm{SXT}=$ trimethoprim/ sulfamethoxazole, $\mathrm{VAN}=$ vancomycin, $\mathrm{ERI}=$ erythromycin, $\mathrm{COL}=$ colistin, $\mathrm{TZP}=$ piperacillin/tazobactam, $\mathrm{MET}=\mathrm{metronidazole}, \mathrm{N} /$ $\mathrm{D}=$ not available. 
Table 2: FMT treatment for recurrent CDI in eight patients.

\begin{tabular}{|c|c|c|c|c|c|c|c|}
\hline Patient & $\begin{array}{c}\text { C.difficile A/B } \\
\text { toxins in stool }\end{array}$ & $\begin{array}{c}\text { ATLAS Score/ } \\
\text { Expected Cure } \\
\text { Rate* }\end{array}$ & $\begin{array}{c}\text { Failure } \\
\text { of Initial } \\
\text { Treatment** }\end{array}$ & $\begin{array}{c}\text { FMT } \\
\text { Date }\end{array}$ & Exit By & $\begin{array}{c}\text { Tracing Post- } \\
\text { FMT } \\
\begin{array}{c}\text { Serious } \\
\text { Adverse } \\
\text { Events**** }\end{array}\end{array}$ \\
\hline 1 & Positive & $4 / 80 \%$ & Yes & 29.09 .2016 & Clinical improvement & 2 years 1 month & None \\
\hline 2 & Positive & N/D & Yes & 21.04 .2017 & Clinical improvement & 1 year 6 months & None \\
\hline 3 & Positive & $2 / 90 \%$ & Yes & 25.05 .2017 & Self-will & N/D & N/D \\
\hline 4 & Positive & $2 / 90 \%$ & Yes & 13.09 .2017 & Clinical improvement & 1 year 2 months & None \\
\hline 5 & Positive & $4 / 80 \%$ & Yes\& & 21.03 .2018 & Clinical improvement & 8 months & None \\
\hline 6 & Positive & $0 / 100 \%$ & Yes & 05.11 .2017 & Clinical improvement & 1 year & None \\
\hline 7 & Positive & $3 / 85 \%$ & Yes & 24.01 .2018 & Death*** & - & --- \\
\hline 8 & Positive & $2 / 90 \%$ & Yes & 22.02 .2019 & Clinical improvement & 3 months & None \\
\hline
\end{tabular}

*Planned cure rate with treatment at the expense of vancomycin or fidaxomicin; ${ }^{* *}$ With vancomycin and metronidazole; *** Death not associated with FMT; \& With tigecycline; N/D = not available.

\section{Patient 1}

Male, 77 years old, admitted previously twice, due to central venous catheter (CVC)-associated sepsis and abdominal surgery (laparotomy and intestinal occlusion-solving colostomy), received multiple antimicrobial treatment courses prior to CDI. Although, he was selected for radical colectomy after toxin detection in the feces and a diagnosis of pseudomembranous colitis. A delay in paperwork presented the opportunity to perform FMT, resulting in the resolution of diarrhea within $24 \mathrm{~h}$, improvement of his general condition, and adequate feeding by oral route. Two days later, he was discharged from the hospital in good health.

\section{Patient 2}

Female, 59 years old, without other previous symptoms up to 18 months with the evolution of dysphagia, pyrosis, retrosternal pain, regurgitation, and vomiting, leading to rapid and important weight loss (6 kg). The Gastroenterology Department diagnosed esophagus achalasia through endoscopy, esophagram, and esophageal manometry. Accordingly, a surgeon performed a Heller myotomy maneuver laparoscopically, after which she recovered and was discharged from the hospital $72 \mathrm{~h}$ later. Within 10 days, mucus-bearing diarrheal evacuation, abdominal distention without fever, and negative microbiology culture-oriented suspicion of nosocomial-acquired CDI was reported. Treated as an external patient, oral metronidazole was prescribed; however, she had a barely acceptable response. In the following quarter, she relapsed three times, requiring hospital admission. CDI was then managed with oral vancomycin (decreasing dosages) or rifaximin (last episode) until FMT was performed without major adverse events during the following 18 months.

\section{Patient 3}

Female, 58 years old, presented at the Emergency Room complaining of acute headache and lip commissure deviation, justifying the admission of her case to the local hospital to receive immediate medical attention. She had loss of headache control 1 month later, and referral to the observation of a top specialist at the National Institute of Neurology and Neurosurgery (INNN) in Mexico City, being diagnosed an intracranial aneurysm, which was surgically resected, whereby her condition stabilized temporarily. Early in her clinical evolution however, a recurrent CDI was confirmed after the failure of a 10-day antimicrobial prescription. When the patient received a diagnosis of FMT 5 days later, her legal guardian decided to withdraw her from the protocol, as there was no indication of relief of the CDI symptoms.

\section{Patient 4}

Female, 35 years old, presented 30 days prior to hospital admission exhibiting muscular weakness of the lower limbs due to dorsal infectious spondylodiscitis that compressed the medulla, resulting in urinary sphincter function being affected and paraplegia. Surgical column stabilization was necessary in that meropenem did not improve her motor reflexes; diarrhea compatible with $\mathrm{C}$. difficile and a prolonged hospital stay was treated according to clinical guidelines, albeit unsuccessfully. She was recruited into the allogenic FMT protocol, showing an improved clinical condition as evidenced by normalization of evacuation frequency and fecal characteristics $48 \mathrm{~h}$ following the allogenic FMT, thus allowing the Urology Service to manage a neurogenic bladder drain via urinary catheter.

\section{Patient 5}

Female, 84 years old, complained of strong headache followed by motor function deterioration, justifying neurological evaluation at INNN. Angiography demonstrated anterior communicating artery aneurysm, which was embolized. During her recovery, C. difficile toxins were detected as fecal density diminished. Although two cycles of indicated antimicrobial treatment were maintained along the following 10 days, no improvement was registered. Therefore, the Neuro-Infectology Department requested legal 
permission from her guardian to perform FMT. Her CDI symptoms gradually waned, whereas pathological evacuation only remitted 11 days post-FMT. She continued to be fed through a nasogastric catheter until a successful gastrostomy was performed. Four days after the surgery, the patient was discharged from the hospital.

\section{Patient 6}

Male, 47 years old, Human Immunodeficiency virus (HIV)positive since 2007 , currently at stage $3 \mathrm{C}$ while seeking medical advice for third cranial nerve pair (NCIII) neurosyphilis neuralgia at INNN, where a wide-spectrum antimicrobial was prescribed. Later, during his hospital stay, he developed fluid and electrolyte imbalance in addition to being unaffected by CDI-suitable antimicrobial therapy. Therefore, FMT was administered under the protocol, and he showed showing significant improvement by $24 \mathrm{~h}$, and was discharged from the hospital 6 days later. Follow-up continued as described previously.

\section{Patient 7}

Male, 47 years old, complaining of intense headache plus vomiting; sought medical evaluation at the local primary-level facility at Atlacomulco, State of Mexico. Was diagnosed with a urinary tract infection (UTI) and received antimicrobials and analgesics. His neurological symptoms persisted, and leg weakness developed. Over the following $72 \mathrm{~h}$, his consciousness deteriorated, requiring mechanical respiratory aid, and he was transferred to the tertiarylevel INNN. Angiography showed a right frontal cerebral artery aneurysm, which was embolized; however, bifrontal infraction and ischemia data attributable to vasospasm data had already been established. Although the patient underwent canalization at the critical care unit (CCU) that included standard pharmacological treatment, CDI diarrhea refractory to 20-day antimicrobial treatment occurred, for which FMT was administered, causing the remission of diarrhea within $24 \mathrm{~h}$. Unfortunately, multiorgan failure evolved 4 days later, and simultaneous hemodynamic stability and respiratory failure worsened. Despite the prescription of vasopressors, the patient died.

\section{Patient 8}

Female, 27 years old, admitted to the INNN showing altered behavior in recent days, including behavioral changes, erratic mental function, and altered awareness, followed by progressively intensified dyskinesia and convulsions; autoimmune encephalitis with anti-NMDA (N-methyl-D-aspartate) antibodies was assessed. Nevertheless, her blood oxygen was diminished due to deteriorated ventilatory gas exchange, which prompted intubation and admission to the CCU for immediate plasmapheresis (seven sessions) plus an anticonvulsive drug in addition to a wide-spectrum antimicrobial treatment due to the presence of pneumonia. The latter required airway management with assisted mechanical ventilation, which was later de-escalated according to the antibiogram, and gastrectomy was performed as well. Hence, she subsequently developed CDI. Clinical evolution accelerated, showing nonprofuse diarrhea, diminished bowel movements, and abdominal distention of up to $8 \mathrm{~cm}$, as revealed by computed tomography (CT). Nonetheless, the imaging scan discarded colonic perforation, and rectorrhagia requiring red cell transfusion was confirmed. In fact, a significant symptom of amelioration took place only $24 \mathrm{~h}$ after allogenic FMT. Diarrhea has not recurred after 7 months of followup.

\section{Discussion}

Several CDI reports and prospective trials have indicated that the incidence in Mexico approached at least 11.5 cases per 100,000 and that the C. difficile-associated disease (CDAD)-related ageadjusted case-fatality rate rose from $1.2 \%$ in 2000 to $2.2 \%$ in 2004 $[23,24]$. In that the best antimicrobial treatment available fails in at least two of every eight patients [25], it is clear that a solution for restoring gut microbiota function and breaking the chronic pattern is of utmost importance $[7,26]$. FMT has shown promising results for various conditions and is particularly effective for resolving recurrent CDI $[8,9,17]$. In our case series, the $83 \%$ efficacy of FMT achieved was within range currently $80-100 \%$ frequently reported for CDI treatment among CDI patients $[9,10,27]$. The main differences with previous case reports is the fact that our patients had baseline affectations involving the gut-brain axis, surgeries or autoimmune deficiency. Other differences that should be emphasized are the follow-up provided to our patients before requiring the FMT, where the different antimicrobials administered for their basal pathology highly related to the opportunism of C. difficile and for attempting to eradicate the pathogen were also evaluated. Primarily, wide-spectrum, but also long and/or periodic, antimicrobial treatment preceded hospital-acquired CDI in all cases; $20 \%$ of our patients were aged $>65$ years. Of the eight patients in our study, two had undergone abdominal surgery prior to symptom debut. In spite of brain trauma and neurologic disease involving aneurysm formation, our patients might be circumscribed in a particular group, in that prolonged hospital stays concurred with broad microbiota insult before CDI presentation. Interestingly, dysbiosis has been demonstrated in experimental animals after CNS vascular events, in addition to a substandard clinical trend in affected human subjects [28].

However, we did not control for severity in the present case series; we note that, in one patient, diarrhea continued at least 10 days after the patient withdrew from the study, whereas for a second patient (3), recovery from CDI was difficult and took $>9$ days. Although we reported that one patient died, the causenosocomial pneumonia-was not related to FMT. Otherwise, it can be argued that the CDI symptoms of the majority of the patients 
ceased within $24 \mathrm{~h}$, permitting the management of subjacent disease. It should be noted that, in our case series, there were no adverse events directly related to FMT. On the other hand, the eligibility of immunocompromised patients for FMT on the grounds of efficacy and safety is controversial; however, Shogbesan and colleagues identified a median $88 \%$ and $93 \%$ efficacy after one or more FMT procedures, respectively [29]. The present case series included an HIV-positive patient with stage 3C AIDS who had also been diagnosed with neurosyphilis when FMT was performed and remarkable improvement of CDI was noted after only $24 \mathrm{~h}$ of FMT, with no adverse events.

Finally, in the present study, FMT was proven to be safe and effective, achieving our stated objective, while ignorance of the procedure and common mild adverse events continue to be the main reasons for the low acceptance. Our study provides the necessary examples for establishing solid criteria in patients with recurrent CDI.

\section{Author Contributions}

Y.LV.: contributed with study concept, supervised, analyses, grant support, wrote and reviewed the manuscript; J.L.S.H.: performed the enrollment patients, supervised and perform FMT; R.A.H: participated in enrollment of donors and the elaboration of FMT protocols; P.O.: contributed in the elaboration of FMT protocols, analyses of donation samples and review the manuscript. M.J.S. and A.M.Z.: carried out in enrollment patients and performed the FMT; A.C.C.T and A.G.H.: participated in follow- up of patients, performed the analyses of cases and wrote the manuscript; A.M.V. and G.C.: analyses of donation samples and review the manuscript; S.P.L: contributed to study concept, coordination, supervision, wrote and reviewed the manuscript.

\section{Acknowledgments}

This study was financed by grant IV200315 and IA207918 from PAPIIT-UNAM. Also, we receive a donation from Fundación Miguel Aleman A.C. and Fundación Gonzalo Río Arronte I.A.P.

\section{References}

1. Bartlett JG (2017) Clostridium difficile Infection. Infectious Disease Clinics of North America 31(3): 489-495.

2. Czepiel J, Dróżdż M, Pituch H, Kuijper EJ, Perucki W, et al. (2019) Clostridium difficile infection: review. European Journal of Clinical Microbiology \& Infectious Diseases 38(7): 1211-1221.

3. Zilberberg MD, Shorr AF, Kollef MH (2008) Increase in adult Clostridium difficile-related hospitalizations and case-fatality rate, United States, 2000-2005. Emerging Infectious Diseases 14(6): 929-931.

4. Kimura T, Stanhope S, Sugitani T (2020) Excess length of hospital stay, mortality and cost attributable to Clostridioides (Clostridium) difficile infection and recurrence: A nationwide analysis in Japan. Epidemiology and Infection 148: e65.

5. Vedantam G, Clark A, Chu M, McQuade R, Mallozzi M, et al. (2012) Clostridium difficile infection: Toxins and non-toxin virulence factors, and their contributions to disease establishment and host response. Gut Microbes 3(2): 121-134.
6. Arredondo-Hernandez R, Orduña-Estrada P, Lopez-Vidal Y, Ponce de Leon-Rosales S (2018) Clostridium Difficile Infection: An Immunological Conundrum. Archives of Medical Research 49(6): 359-364.

7. Chang JY, Antonopoulos DA, Kalra A, Tonelli A, Khalife WT, et al. (2008) Decreased Diversity of the Fecal Microbiome in Recurrent Clostridium difficile -Associated Diarrhea. The Journal of Infectious Diseases. 197(3): 435-438

8. Moayyedi P, Yuan Y, Baharith H, Ford AC (2017) Faecal microbiota transplantation for Clostridium difficile -associated diarrhoea: a systematic review of randomised controlled trials . Medical Journal of Australia 207(4): 166-172.

9. Quraishi MN, Widlak M, Bhala N, Moore D, Price M, et al. (2017) Systematic review with meta-analysis: the efficacy of faecal microbiota transplantation for the treatment of recurrent and refractory Clostridium difficile infection. Alimentary Pharmacology and Therapeutics 46(5): 479-493.

10. Kelly CR, Yen EF, Grinspan AM, Kahn SA, Atreja A, et al. (2021) Fecal Microbiota Transplantation Is Highly Effective in Real-World Practice: Initial Results from the FMT National Registry. Gastroenterology 160(1): 183-192.e3.

11. Ooijevaar RE, Terveer EM, Verspaget HW, Kuijper EJ, Keller JJ (2019) Clinical Application and Potential of Fecal Microbiota Transplantation. Annual Review of Medicine 70: 335-351.

12. Bouri S, Hart A (2018) Fecal microbial transplantation: an update. Current opinion in clinical nutrition and metabolic care 21(5): 405-410.

13. Green JE, Davis JA, Berk M, Hair C, Loughman A, et al. (2020) Efficacy and safety of fecal microbiota transplantation for the treatment of diseases other than Clostridium difficile infection: a systematic review and metaanalysis. Gut Microbes 12(1): 1-25.

14. Petra AI, Panagiotidou S, Hatziagelaki E, Stewart JM, Conti P, et al. (2015) Gut-Microbiota-Brain Axis and Its Effect on Neuropsychiatric Disorders with Suspected Immune Dysregulation. Clinical therapeutics 37(5): 984-995.

15. Vendrik KEW, Ooijevaar RE, de Jong PRC, Laman JD, van Oosten BW, et al. (2020) Fecal Microbiota Transplantation in Neurological Disorders. Frontiers in Cellular and Infection Microbiology 10: 98.

16. Kelly CR, Ihunnah C, Fischer M, Khoruts A, Surawicz C, et al. (2014) Fecal microbiota transplant for treatment of Clostridium difficile infection in immunocompromised patients. The American journal of gastroenterology 109(7): 1065-1071.

17. van Nood E, Vrieze A, Nieuwdorp M, Fuentes S, Zoetendal EG, et al. (2013) Duodenal infusion of donor feces for recurrent clostridium difficile. New England Journal of Medicine 368: 407-415.

18. Abu-Sbeih H, Ali FS, Wang Y (2019) Clinical Review on the Utility of Fecal Microbiota Transplantation in Immunocompromised Patients. Current Gastroenterology Reports 21(4): 8.

19. Sartelli M, di Bella S, McFarland Lv, Khanna S, Furuya-Kanamori L, et al. (2019) 2019 update of the WSES guidelines for management of Clostridioides (Clostridium) difficile infection in surgical patients. World Journal of Emergency Surgery 14: 1-29.

20. McDonald LC, Gerding DN, Johnson S, Bakken JS, Carroll KC, et al. (2018) Clinical Practice Guidelines for Clostridium difficile Infection in Adults and Children: 2017 Update by the Infectious Diseases Society of America (IDSA) and Society for Healthcare Epidemiology of America (SHEA). Clinical infectious diseases: an official publication of the Infectious Diseases Society of America 66(7): 987-994.

21. Cammarota G, Ianiro G, Tilg H, Rajilić-Stojanović M, Kump P, et al. (2017) European consensus conference on faecal microbiota transplantation in clinical practice. Gut 66(4): 569-580.

22. Abreu y Abreu AT, Velarde-Ruiz Velasco JA, Zavala-Solares MR, RemesTroche JM, Carmona-Sánchez RI, et al. (2019) Consensus on the 
prevention, diagnosis, and treatment of Clostridium difficile infection. Revista de Gastroenterologia de Mexico 84(2): 204-219.

23. Álvarez-Hernández DA, González-Chávez AM, González-HermosilloCornejo D, Franyuti-Kelly GA, Díaz-Girón-Gidi A, et al. (2018) Present and past perspectives on Clostridium difficile infection. Revista de Gastroenterologia de Mexico 83(1): 41-50.

24. Ramírez-Rosalesa A, Cantú-Llanos E (2012) In-hospital mortality in patients with diarrhea associated with Clostridium difficile infection. (Mortalidad intrahospitalaria en pacientes con diarrea asociada a infección por Clostridium difficile). Revista de Gastroenterologia de Mexico 77(2): 60-65.

25. Olsen MA, Yan Y, Reske KA, Zilberberg MD, Dubberke ER (2015) Recurrent Clostridium difficile infection is associated with increased mortality. Clinical Microbiology and Infection 21(2): 164-170.

26. Zanella Terrier MC, Simonet ML, Bichard P, Frossard JL (2014) Recurrent Clostridium difficile infections: The importance of the intestinal microbiota. World Journal of Gastroenterology 20(23): 7416-7423.

\section{ISSN: 2574-1241}

DOI: $10.26717 /$ BJSTR.2021.36.005905

Samuel Ponce de León-Rosales. Biomed J Sci \& Tech Res

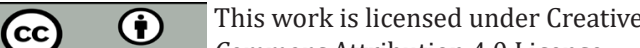

Submission Link: https://biomedres.us/submit-manuscript.php
27. Cammarota G, Masucci L, Ianiro G, Bibbò S, Dinoi G, et al. (2015) Randomised clinical trial: Faecal microbiota transplantation by colonoscopy vs. vancomycin for the treatment of recurrent Clostridium difficile infection. Alimentary Pharmacology and Therapeutics 41(9): 835-843.

28. Shikata F, Shimada K, Sato H, Ikedo T, Kuwabara A, et al. (2019) Potential Influences of Gut Microbiota on the Formation of Intracranial Aneurysm. Hypertension 73(2): 491-496.

29. Shogbesan O, Poudel DR, Victor S, Jehangir A, Fadahunsi O, et al. (2018) A Systematic Review of the Efficacy and Safety of Fecal Microbiota Transplant for Clostridium difficile Infection in Immunocompromised Patients. Canadian Journal of Gastroenterology and Hepatology 2018: 1394379.

$\begin{array}{ll}\text { BIOMEDICAL } & \text { Assets of Publishing with us } \\ \text { RESEARCHES } & \text { - Global archiving of articles } \\ \text { - Immediate, unrestricted online access }\end{array}$

